\title{
PENILAIAN DAYA TARIK OBJEK WISATA PANTAI DI DESA TEMAJUK KECAMATAN PALOH KABUPATEN SAMBAS KALIMANTAN BARAT
}

\author{
(Assessment of Attraction of Coastal Tourism Objects in Temajuk Village, Paloh District, \\ Sambas District, West Kalimantan)
}

\author{
Khairil Fitrian, Harnani Husni, Sarma Siahaan \\ Fakultas Kehutanan Universitas Tanjungpura Jalan Daya Nasional Pontianak 78124 \\ E-mail: putrakieytra@gmail.com
}

\begin{abstract}
Temajuk Beach area is one of the tourism potentials that is not yet known by the wider community, which is located in Temajuk Village, Paloh District, Sambas Regency. Temajuk Beach has great potential when it is used as a tourist spot because the location of Temajuk Beach has beautiful beaches and unspoiled scenery, a lack of government contribution to make the place a tourist attraction. The purpose of the research is to find out the potential of coastal attraction at Temajuk Beach and do an assessment of the potential attractiveness of Temajuk Beach in Sambas Regency, West Kalimantan Province, especially for coastal tourism. The study was conducted in Temajuk Village, Paloh Subdistrict, Sambas District for 4 weeks. Based on the results of the study, the appraisal of attractiveness got the highest score of 1013.58 (A) assessment of clean water availability of 780 accessibility scores of $550(C)$, and assessment the supporting infrastructure received a score of 720 so that it was included in the medium category $(B)$, the assessment of the socio-economic conditions of the community got a score of 425 so that it was included in the medium category $(B)$, while the accommodation scored the lowest value 180 and included in the category good (A). The assessment of each rating element that has been classified and then summed and gets an average total value of 611.43 from the results obtained when classified with the 2003 ODTWA PHKA development class, Temajuk Beach area gets a value (B) which means Temajuk Beach area good to be developed as a place/tourist attraction.
\end{abstract}

Keyword: Potential of Coastal Ecotourism, Regency of Sambas, Temajuk Beach.

\section{PENDAHULUAN}

Ekowisata muncul sebagai salah satu alternatif solusi peningkatan apresiasi masyarakat terhadap alam, karena ekowisata merupakan perjalanan yang bertanggung jawab ketempattempat yang alami dengan menjaga kelestarian lingkungan dan meningkatkan kesejahteraan penduduk setempat serta dapat memberi manfaat ekonomi sebagai salah satu Pendapatan Asli Daerah (PAD). Potensi wisata adalah berbagai sumber daya yang terdapat di sebuah daerah tertentu yang bisa dikembangkan menjadi atraksi wisata. Dengan kata lain, potensi wisata adalah berbagai sumber daya yang dimiliki oleh suatu tempat dan dapat dikembangkan menjadi suatu atraksi wisata (tourist attraction) yang dimanfaatkan untuk kepentingan ekonomi dengan tetap memperhatikan aspek-aspek lainnya (Pendit,2006).

Pantai Temajuk merupakan objek wisata yang belum mendapatkan 
perhatian serius dari pemerintah setempat. Menurut Firmansyah dan Yoswati (2012) pengelolaan ekowisata akan dapat berjalan dengan baik pada setiap kecamatan apabila bertujuan mendukung pembangunan pariwisata berkelanjutan dengan berasaskan pada prinsip ekowisata yaitu menyelaraskan antara pengelolaan lingkungan hidup, pengelolaan ekosistem dan pembangunan ekowisata. Pengelolaan di lakukan sebelum terjadi kerusakan sumberdaya alam dan menurunya kualitas hidup masyarakat lokal.

Pantai Temajuk merupakan salah satu Pantai yang terdapat di Desa Temajuk Kecamatan Paloh di Kabupaten Sambas Provinsi Kalimantan Barat berbatasan langsung dengan negara Malaysia. Di Kecamatan Paloh itu sendiri terdapat wisata yang belum banyak di ketahui keberadaanya oleh masyarakat luas, potensi tersebut berada di Desa Temajuk, potensi wisata Pantai Temajuk memiliki pemandangan alam yang menarik untuk di kunjungi serta masih memiliki udara yang segar dan alami namun sampai saat ini belum ada instansi terkait yang berminat melakukan peninjauan untuk tempat tersebut sebagai objek wisata karena kurangnya informasi yang spesifik tentang potensi wisata secara detail serta lokasinya yang jauh.

Sebagai daerah yang dapat dijadikan tujuan wisata yang memiliki ciri khas ketika air laut surut menyisakan hamparan pasir yang sangat luas dengan lebar 100-150 meter, namun ketika memasuki bulan oktober - februari tiupan angin yang kencang dan tinggi gelombang di pantai ini bisa mencapai 2 meter bahkan lebih sehingga bisa untuk olahraga berselancar, penyu penyu yang bertelur di pesisir pantai serta aktifitas masyarakat mengelola ubur ubur, bebatuan yang indah tersusun alami dari yang kecil sampai berukuran besar. Pantai Temajuk sangatlah menarik untuk dijadikan sebagai objek wisata, disisi lain pengembangan ekowisata di Pantai Temajuk Kecamatan Paloh Kabupaten Sambas membutuhkan penunjang yang memadai agar meningkatkan intensitas kunjungan yang diharapkan berpengaruh terhadap tingkat sosial ekonomi masyarakat setempat melalui peluang usaha industri ekowisata. Tujuan dari penelitian ini adalah untuk memperoleh data mengenai potensi daya tarik yang terdapat pada kawasan wisata Pantai Temajuk, serta melakukan penilaian potensi daya tarik terhadap kawasan wisata Pantai Temajuk Kecamatan Paloh Kabupaten Sambas.

\section{METODE PENELITIAN}

Penelitian dilaksanakan di Pantai Temajuk Kecamatan Paloh Kabupaten Sambas Kalimantan Barat, pada tanggal 23 januari sampai 10 februari 2017. Pengambilan sampel responden pengunjung menggunakan accidental sampling, Kriteria pengunjung yang dijadikan responden yaitu sehat jasmani 
rohani, berumur minimal 17 tahun, mampu berkomunikasi dengan baik, mampu membaca dan menulis serta mengetahui kondisi kawasan objek wisata Pantai Temajuk.

Kriteria potensi ODTWA yang dinilai, antara lain; daya tarik wisata, aksesibilitas, kondisi lingkungan sosial ekonomi, akomodasi, prasarana dan sarana penunjang. Teknik pengumpulan data di lapangan dalam penelitian ini meliputi metode observasi, yaitu pengamatan dan pencatatan sesuatu objek secara langsung di lapangan dengan sistematik, selanjutnya dilakukan dengan menggunakan metode deskriptif dalam bentuk survey dengan teknik wawancara dibantu dengan kuisioner. Analisis data menggunakan metode skoring dengan menggunakan Pedoman Analisis Daerah Operasi Objek dan Daya Tarik Wisata Alam (ADO-ODTWA) Direktorat Jenderal PHKA tahun 2003 yang telah dimodifikasi sesuai dengan nilai/skor yang telah ditentukan untuk masing masing kriteria. Jumlah nilai untuk satu kriteria penilaian ODTWA dapat dihitung dengan persamaan sebagai berikut:

dengan rumus:

$$
\mathrm{S}=\mathrm{N} \times \mathrm{B}
$$

Keterangan :

$\mathrm{S}=$ skor/nilai suatu kriteria

$\mathrm{N}=$ jumlah nilai-nilai unsur pada krieria

$\mathrm{B}=$ bobot nilai

Kemudian hasil dari nilai yang telah didapat dibandingkan lagi dengan nilai klasifikasi pengembangan dari masing masing kriteria penilaian, setelah itu nilai bobot/klas yang telah didapat dari tabulasi klasifikasi pengembangan dari masing masing kriteria penilaian, nilai dari masingmasing kriteria tersebut dirata ratakan kelas baik, sedang, dan buruk untuk mendapatkan hasil akhir penilaian obyek wisata Pantai Temajuk dapat dilihat pada Tabel 1.

Tabel 1. Klasifikasi Unsur Pengembangan Berdasarkan Nilai Bobot Setiap Kriteria Penilaian (Classification of Development Element Based on Weight Each Assessment)

\begin{tabular}{lll}
\hline No & Nilai Total & Penilaian Potensi Unsur \\
\hline 1 & $660-879$ & Sangat Potensial dikembangkan (A) \\
2 & $480-659$ & Baik untuk dikembangkan (B) \\
3 & $281-479$ & Tidak Potensial dikembangkan (C) \\
\hline
\end{tabular}

\section{HASIL DAN PEMBAHASAN}

Hasil perhitungan dari setiap unsur dan sub unsur pada kriteria daya tarik obyek wisata yang berdasarkan pada pedoman Penilaian ODTWA PHKA 2003 pada tabel 2. 
Tabel 2. Perhitungan Seluruh Kriteria Daya Tarik Obyek Wisata Pantai di Desa Temajuk (Calculation of all criteria for attraction of coastal tourism objects in Temajuk Village).

\begin{tabular}{|c|c|c|c|}
\hline No & Unsur dan Sub Unsur & Nilai & $\%$ \\
\hline 1 & $\begin{array}{l}\text { Keindahan: } \\
\text { a. Variasi pandangan pantai/ gunung di laut } \\
\text { b. Keindahan pantai } \\
\text { c. Keserasian pandangan pantai dan sekitarnya }\end{array}$ & 19,87 & $11,76 \%$ \\
\hline 2 & $\begin{array}{l}\text { Keselamatan / keamanan pantai : } \\
\text { a. Tidak ada arus balik berbahaya } \\
\text { b. Tidak ada kecuraman dasar } \\
\text { c. Bebas gangguan binatang berbahaya } \\
\text { d. Tidak ada kepercayaan yang mengganggu } \\
\text { e. Tidak ada gangguan manusia }\end{array}$ & 12,95 & $7,66 \%$ \\
\hline 3 & Pasir & 20,37 & $12,05 \%$ \\
\hline 4 & $\begin{array}{l}\text { Variasi Kegiatan: } \\
\text { a. Berjemur } \\
\text { b. Selancar } \\
\text { c. Berenang } \\
\text { d. Menikmati pemandangan } \\
\text { e. Olahraga } \\
\text { f. } \text { Bersampan } \\
\end{array}$ & 25,00 & $14,80 \%$ \\
\hline 5 & $\begin{array}{l}\text { Kebersihan pantai : } \\
\text { a. Tidak ada pengaruh pelabuhan } \\
\text { b. Tidak ada pengaruh pemukiman } \\
\text { c. Tidak ada pengaruh sungai } \\
\text { d. Tidak ada pengaruh pelelangan Ikan/pabrik/pasar } \\
\text { e. Tidak ada sumber pencemaran lain } \\
\text { f. Tidak ada pengaruh musim }\end{array}$ & 22,7 & $13,44 \%$ \\
\hline
\end{tabular}

6 Kejernihan air tampak sampai kedalaman (m)
a. $15,0-12,5$
b. $12,4-10,0$
c. $9,9-7,5$
14,80
$8,77 \%$
d. $7,4-5,0$

a. $4,9-2,5$

\begin{tabular}{llcc}
\hline 7 & Banyaknya lokasi yang mempunyai kedalaman yang sama & 27,87 & $16,50 \%$ \\
\hline 8 & Situasi pandangan dan kenyamanan : & & \\
& $\begin{array}{l}\text { a. Rindang } \\
\text { b. Pasir putih }\end{array}$ & 25,37 & $15,02 \%$ \\
& c. Bersih & & \\
d. Pandangan indah & & \\
e. Tidak ada gangguan & 168,93 & $100 \%$ \\
\hline
\end{tabular}

Hasil penelitian, banyaknya lokasi yang mempunyai kedalaman yang perairan sama di areal obyek wisata menunjukkan nilai skor tertinggi dari unsur dan sub unsur yang telah dinilai sebesar 27,87 dengan persentasi $16,50 \%$. Sedangkan skor nilai terendah terdapat pada keselamatan dan keamanan pantai dengan nilai sebesar 12,95 dan persentase sebesar 7,66 \% . Dari hasil penelitian secara keseluruhan unsur dan sub unsur yang telah dinilai mendapatkan jumlah nilai sebesar 168,93. Nilai yang telah didapat dikalikan dengan bobot nilai 6 untuk kriteria penilaian daya tarik wisata 
sehingga mendapatkan nilai 1013,58. Nilai yang telah didapat dimasukkan didalam klasifikasi usaha pengembangan obyek wisata, maka kawasan wisata Pantai Temajuk memiliki daya tarik yang bernilai baik (A).

Penilaian Aksesibilitas.

Tabel 3. Hasil Perhitungan Penilaian Aksesibilitas (Calculation of accessibility assessment)

\begin{tabular}{ccc}
\hline No & Unsur/Sub Unsur & Skor \\
\hline 1 & Kondisi dan Jarak Jalan darat & \\
& $<5 \mathrm{~km}$ & 40 \\
& $5-10 \mathrm{~km}$ & 15 \\
& $10-15 \mathrm{~km}$ & 5 \\
& $>15 \mathrm{~km}$ & - \\
2 & Tipe Jalan & 30 \\
3 & Waktu tempuh dari pusat kota & 20 \\
\hline & Jumlah & 110 \\
\hline
\end{tabular}

Berdasarkan hasil nilai skor keseluruhan penilaian didapat dengan hasil 110, maka dikalikan dengan nilai bobot kriteria penilaian Aksesibilitas. Nilai bobot kriteria Aksesibilitas memiliki nilai 5, sehingga nilai kriteria aksesibilitas di Pantai Temajuk menjadi $110 \times 5=550$, setelah itu nilai tersebut di klasifikasikan dengan klasifikasi pengembangan ODTWA maka kriteria penilaian aksesibilitas di Pantai Temajuk memasuki katagori nilai yang buruk (C).

Tabel 4. Hasil Kondisi Sosial Ekonomi (Calculation of Socioeconomic Condition)

\begin{tabular}{rccc}
\hline & No & Unsur/Sub Unsur & Skor \\
& 1 & Tata Ruang Wilayah Obyek & 15 \\
& Status Lahan & 30 \\
3 & Mata Pencaharian Penduduk & 20 \\
4 & Pendidikan & 20 \\
\hline Hasil & penelitian yang telah & nilai skor yang didapat dari pengamatan \\
dilakukan di lapangan untuk kriteria & langsung dilapangan sebesar 85. Nilai \\
penilaian kondisi sosial ekonomi di & skor yang telah didapat dikalikan \\
areal Pantai Temajuk status lahannya & dengan bobot yang ada di kriteria \\
adalah hutan negara, sedangkan jumlah & kondisi sosial ekonomi, nilai nobot
\end{tabular}


untuk kondisi sosial ekonomi adalah 5. Sehingga nilai yang diperoleh dari kriteria kondisi sosial ekonomi menjadi $85 \times 5=425$, setelah itu hasil tersebut apabila diklasifikasikan dengan klasifikasikan sosial ekonomi di Pantai Temajuk mendapatkan nilai Sedang (B).

\section{Akomodasi}

Akomodasi merupakan salah satu faktor yang diperlukan dalam kegiatan wisata, terutama para pengunjung yang datang dari luar daerah yang cukup jauh jaraknya dari lokasi wisata tersebut sehingga membutuhkan akomodasi Tabel 5. Hasil penilaian Akomodasi (calculation of Accommodation)

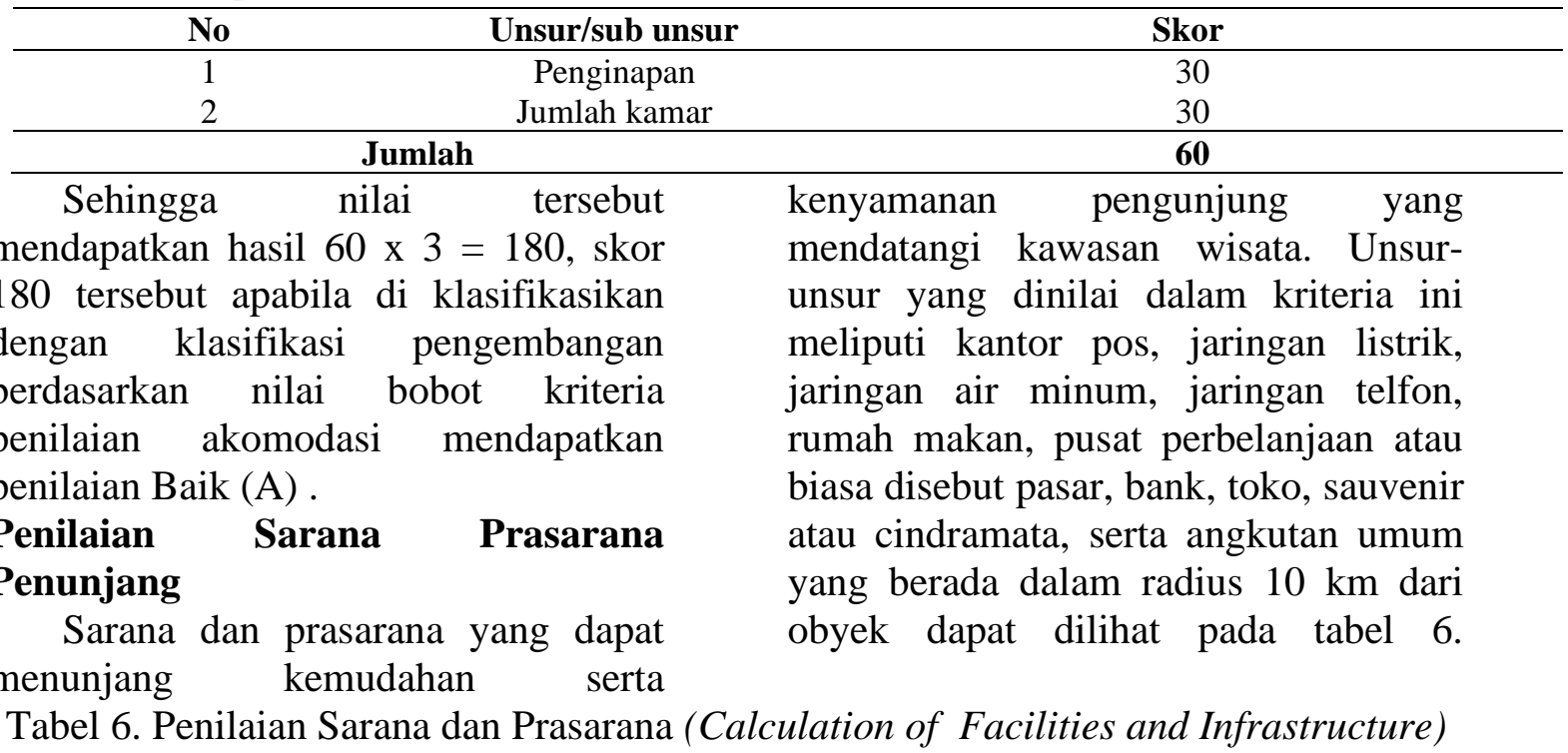

\begin{tabular}{clcc}
\hline No & \multicolumn{1}{c}{ Unsur/sub Unsur } & Jumlah & Skor \\
\hline 1 & Prasarana : & & \\
& kantor pos & - & 10 \\
& jaringan listrik & 1 & 20 \\
& jaringan air minum & 3 & 40 \\
& jaringan telepon & 1 & 10 \\
& Sarana Penunjang : & & \\
& Rumah Makan & 2 & 30 \\
& pusat perbelanjaan / pasar & 1 & 20 \\
& Bank & - & 10 \\
& Toko & $\leq 4$ & 50 \\
& Souvenir/ Cinderamata & 2 & 30 \\
& Angkutan Umum & 1 & 20 \\
\hline & Jumlah & $\mathbf{2 4 0}$ \\
&
\end{tabular}


Hasil penelitian kriteria penilaian sarana prasarana penunjang mendapatkan skor sebesar 240. Hasil skor yang telah didapat dikalikan dengan nilai bobot kriteria penilaian sarana prasarana penunjang bobotnya adalah 3 , sehingga nilai untuk kriteria sarana prasarana penunjang kawasan sekitar Pantai Temajuk menjadi 240 × $3=720$. Nilai tersebut apabila diklasifikasikan dengan nilai skor pada klasifikasi pengembangan kriteria penilaian sarana prasarana penunjang tergolong pada katagori sedang (B).

\section{Penilaian Ketersedian Air Bersih}

Air bersih adalah hal yang paling dibutuhkan oleh setiap manusia untuk keperluan hidup sehari-hari yang banyak memerlukan air bersih. Ketersedian air bersih juga merupakan faktor yang harus tersedia dalam pengembangan suatu obyek wisata, baik untuk pengelolaan maupun pelayanan, unsur yang dinilai meliputi volume/ kecukupan air, jarak sumber air terhadap lokasi obyek, dapat tidaknya/ kemudahan air dialirkan ke obyek, kelayakan dikonsumsi dan kontinuitas dapat dilihat pada tabel 7.

Tabel 7. Ketersedian Air Bersih (Avaibility of Sanitary Water)

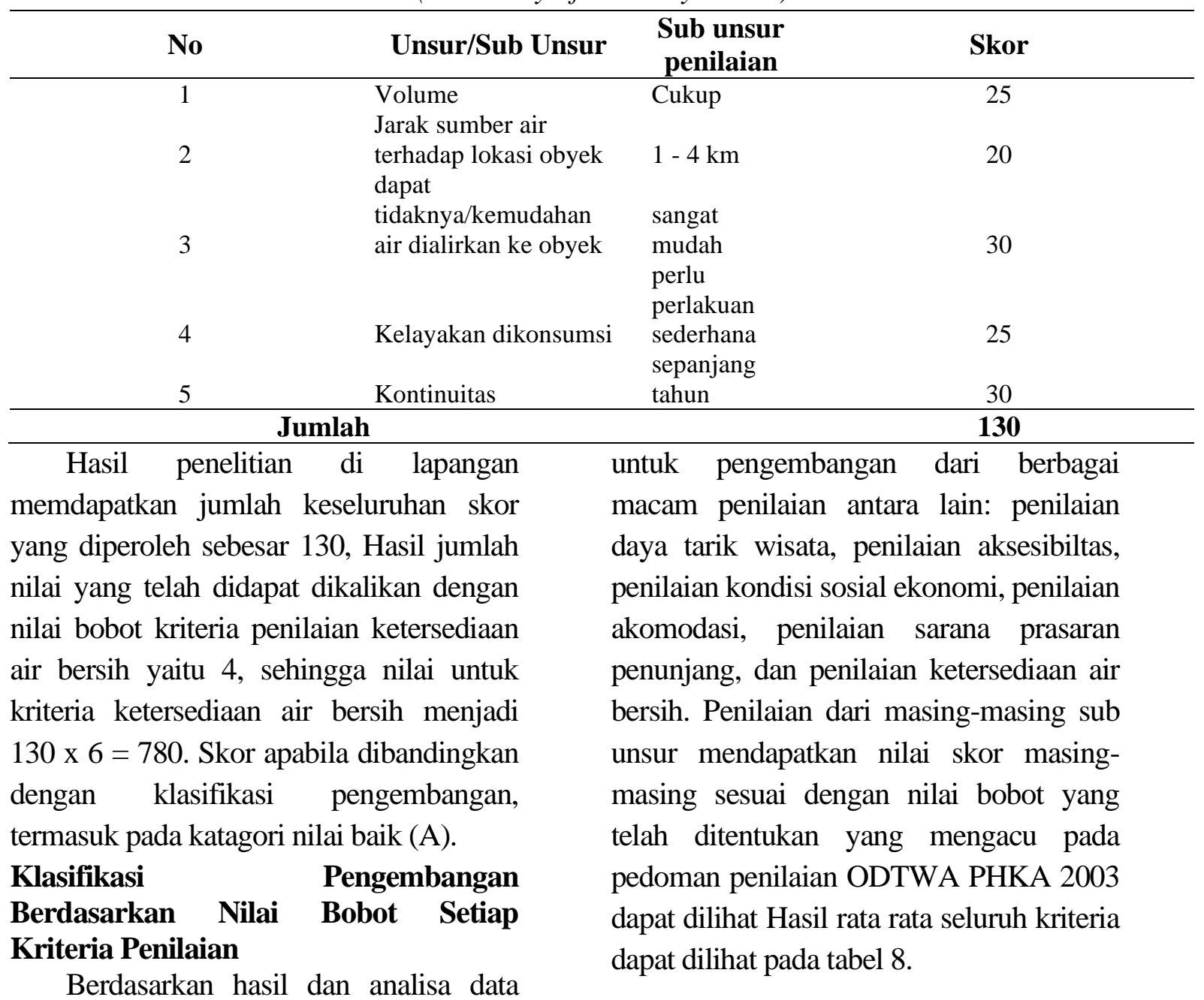

yang telah dilakukan klasifikasi unsur 
Tabel 8. Hasil Perhitungan Setiap Kriteria Penilaian Berdasarkan Standar Baku Klasifikasi Pengembangan ODTWA PHKA 2003 (results of calculation every citeria Classified with the 2003 ODTWA PHKA)

\begin{tabular}{|c|c|c|c|}
\hline No & Kriteria Penilaian & Nilai/skor & Klasifikasi \\
\hline 1 & Penilaian daya tarik wisata & 1013,58 & Baik (A) \\
\hline 2 & Penilaian aksesibilitas & 550 & Buruk (C) \\
\hline 3 & $\begin{array}{l}\text { Penilaian kondisi lingkungan sosial } \\
\text { ekonomi }\end{array}$ & 425 & Buruk (B) \\
\hline 4 & Penilaian akomodasi & 180 & Baik (A) \\
\hline 5 & Penilaian sarana prasarana penunjang & 720 & Baik (A) \\
\hline 6 & Penilaian ketersediaan air bersih & 780 & Baik (A) \\
\hline & Skor total penilaian / 6 & $3668,58 / 6=611,43$ & $\begin{array}{l}\text { (B) cukup potensial } \\
\text { untuk dikembangkan }\end{array}$ \\
\hline
\end{tabular}

Berdasarkan hasil analisa yang telah dilakukan dari 6 kriteria penilaian yang berupa daya tarik wisata, kondisi lingkungan sosial ekonomi, akomodasi, aksesibilitas, sarana dan prasaran penunjang dan ketersediaan air bersih yang telah diklasifikasikan ke dalam kelas pengembangan ODTWA PHKA 2003, serta kawasan Pantai Temajuk mendapatkan nilai (B) yang berarti baik untuk dikembangkan sebagai tempat objek wisata pantai, Namun dalam proses pengembangan masih ada yang perlu diperhatikan seperti aksesibilitas pada saat menuju ke lokasi masih tidak memadai.

\section{Kesimpulan}

1. Nilai yang dihasilkan dari seluruh kriteria penilaian daya tarik wisata adalah 611,43 Sehingga menunjukkan daya tarik wisata Pantai Temajuk mendapat nilai (B) yang berarti baik untuk dikembangkan menjadi objek wisata alam

2. Nilai setiap kriteria penilaian dari daya tarik wisata pantai Temajuk yang paling menonjol untuk dikembangkan adalah penilaian daya tarik wisata dengan nilai skor 1013,58 masuk dalam klasifikasi (A) yang berarti sangat baik dikembangkan menjadi objek wisata. Penilaian paling rendah dari setiap kriteria adalah penilaian aksesbilitas yang mendapat nilai 550 masuk dalam klasifikasi (C) berati kawasan pantai Temajuk jauh dari kriteria untuk pengembangan ekowisata.

3. Daya tarik wisata Pantai Temajuk berpotensi dijadikan lokasi penelitian dan juga masih alami, bersih, aman untuk dikunjungi, serta bisa berenang, berjemur, berolahraga dapat dilakukan dikawasan wisata tersebut.

\section{Saran}

1. Diharapkan masyarakat setempat tetap mempertahankan dan menjaga kelestarian potensi wisata yang terdapat dikawasan Pantai Temajuk.

2. Diharapkan pemerintah setempat lebih memperhatikan aksesibilitas menuju obyek wisata Pantai Temajuk, sebaiknya jalannya diperbaiki lagi supaya memiliki daya tarik pengunjung untuk berwisata.

3. Perlu adanya dukungan dari masyarakat setempat dan pemerintah kabupaten dalam upaya pengembangan pariwisata baik pengembangan objek daya tarik 
wisata dan sarana prasarana di kawasan Pantai Temajuk.

\section{DAFTAR PUSTAKA}

[ PHKA ] Perlindungan Hutan dan Konservasi Alam. 2003. Pedoman Analisis Daerah Operasi Obyek dan Daya Tarik Wisata Alam (ADO- ODTWA).Direktorat Jenderal Perlindungan Hutan dan Konservasi Alam. Bogor.

Abdul Razak. 2008. Sifat Dan Karakter Objek Dan Daya Tarik Wisata Alam (Pendekatan Pengelolaan Objek dan Daya Tarik Wisata Alam). Universitas Gajah Mada. Yogyakarta.

Aryanto. 2003. Eviromental Marketing Pada Ekowisata Pesisir Menggerakkan Rakyat Daerah Otonom. Jakarta .

Anonimus. 1993. Ukuran/Standara Baku Penilaian Pengembangan dan Pemanfaatan Obyek Wisata Alam. Jawa Barat: Komisi Kerjasama Penelitian dan Pengembangan Obyek Wisata Alam Bogor. Bogor.

Dahuri, 2003. Keaneka Ragaman Hayati Laut: Aset Pembangunan Berkelanjutan Indonesia

Departemen Kepariwisataan. 2009. Tentang Undang - Undang Kepariwisataan. Jakarta.

Ervinawati. 2012. Penilaian Daya Tarik Objek Wisata Pantai Putri Serayi Kecamatan Jawai Selatan
Kabupaten Sambas. Universitas Tanjungpura. Pontianak.

Hade Irma Wati.2014. Potensi Objek Dan Daya Tarik Pulau Pontiyanak Sebagai Wisata Alam Di Kecamatan Jawai Selatan Kabupaten Sambas.

Fahriansyah dan Yoswaty. 2012. Pembangunan Ekowisata Di Kecamatan Tanjung Balai.

Fandeli Chafid dan Mukhlison. 2000. Pengusahaan Ekowisata. Fakultas Kehutanan Universitas Gajah Mada Yogyakarta. Yogyakarta.

Hutagalung. 2014. Potensi Daya Tarik Taman Wisata Alam Pantai Tanjung Belimbing Di Desa Sebubus Kecamatan Paloh Kabupaten Sambas. [Skripsi]. Fakukultas Tanjungpura. Pontianak.

Ismayudi. 2006. Studi Potensi Wisata Untuk Daya Tarik Ekoturisme Objek Wisata Pulau Kabung Di Kecamatan Sungai Raya Kabupaten Bengkayang. [Skripsi]. Fakultas KehutananUniversitas Tanjungpura. Pontianak.

Nybakken, J. W. 1992 Biologi Laut Suatu Pendekatan Ekologis. PT. Gramedia. Jakarta

Pendit. 2006. Ilmu Pariwisata : sebuah pengantar perdana. Jakarta. 